\title{
HAEMOLYSIS FOLLOWING COPULATION IN MALE RATS
}

\author{
K. BROWN-GRANT, J. M. DAVIDSON*, M. R. SHERWOOD AND \\ C. M. TAPPER $\dagger$
}

Medical Research Council Neuroendocrinology Unit and Department of Human Anatomy, South Parks Road, Oxford OX1 3QX

(Received 3rd Fune 1971)

In the course of a study on the effects of mating on plasma LH concentrations in the rat, a serendipitous finding was that plasma samples collected from male rats shortly after copulation often showed obvious evidence of haemolysis. These observations prompted a more detailed investigation.

Adult Wistar rats were maintained under reversed lighting (lights on from 21.00 to 11.00 hours). Mating tests were carried out under observation in subdued lighting between 14.00 and 18.00 hours. Females were made highly receptive by the subcutaneous injection of $100 \mu \mathrm{g}$ of oestradiol benzoate in oil $48 \mathrm{hr}$ before tests were begun. Under these conditions, a normal ejaculatory series in the male rat consists of some ten to fifteen mounts with brief penile intromissions, separated by short intercopulatory intervals, over a period of 5 to $10 \mathrm{~min}$. The series terminates with an ejaculation which is followed by a postejaculatory interval of several minutes during which no interest in the female is exhibited.

In some tests, males were allowed to mate for 15 or $30 \mathrm{~min}$, during which time one or more ejaculations occurred; in others, the test period was terminated after ten to fifteen intromissions and before ejaculation ('Intromissions only'). In other tests, a strip of smooth zinc oxide plaster was applied to the female so as to occlude the vaginal orifice and the males were allowed to mount over a period of $30 \mathrm{~min}$ but without intromission occurring ('Mounts only'). Erections were induced by the method developed by C. H. Rodgers and J. M. Davidson (unpublished). Rats were injected with sodium pentobarbitone $(25 \mathrm{mg} / \mathrm{kg}$ body weight intraperitoneally), immobilized in a glass cylinder and light pressure applied to the base of the penis. This resulted in continuous moderate venous congestion of the penis with intermittent brief periods of full erection, ten to twenty-nine in $30 \mathrm{~min}$.

Blood samples $(2.0$ to $2.5 \mathrm{ml})$ were obtained from the jugular vein with a heparinized plastic syringe and 25-gauge needle under Avertin (tribromoethanol plus amylene hydrate) anaesthesia and centrifuged under standardized conditions to obtain plasma which was frozen until assayed. No rat was bled more than once in 2 weeks. Plasma haemoglobin $(\mathrm{Hb})$ concentrations were determined

* Permanent address: Department of Physiology, Stanford University, Stanford, California 94305, U.S.A.

+ Medical Research Council Scholar. 
colorimetrically by a benzidine method. Duplicate $50-\mu \mathrm{l}$ samples of plasma or rat $\mathrm{Hb}$ standard in saline $(5$ to $160 \mathrm{mg} / 100 \mathrm{ml}$ ) were added to $1 \mathrm{ml}$ of a solution of $0.5 \mathrm{~g}$ benzidine in $100 \mathrm{ml}$ of $90 \%$ glacial acetic acid A.R. After careful mixing, $1 \mathrm{ml}$ of a $1 \%(\mathrm{w} / \mathrm{v})$ solution of hydrogen peroxide A.R. was added, the reagents mixed and allowed to stand for $1 \mathrm{hr}$ at room temperature. At the end of this time, $10 \mathrm{ml}$ of a $10 \%(\mathrm{w} / \mathrm{v})$ solution of acetic acid were added and the optical density at $5150 \AA$ determined spectrophotometrically against a reagent blank after allowing at least $10 \mathrm{~min}$ for colour stabilization. The standard curve was linear from 0 to $120 \mathrm{mg} / 100 \mathrm{ml}$ and all plasma samples fell in this range. A difference spectrum of a plasma sample showing obvious pink coloration had peaks identical to those of authentic rat $\mathrm{Hb}$.

TABLE 1

PLASMA HAEMOGLOBIN GONCENTRATIONS

\begin{tabular}{|c|c|c|c|c|c|}
\hline & \multirow[b]{2}{*}{ Status } & \multicolumn{4}{|c|}{ Test } \\
\hline & & 15-min copulation & 30-min copulation & $\begin{array}{l}\text { Mounts only } \\
(30 \mathrm{~min})\end{array}$ & $\begin{array}{c}\text { Test cage } 30 \text { min } \\
\text { no females }\end{array}$ \\
\hline \multirow[t]{2}{*}{$\begin{array}{l}\text { Exp. } 1 \\
\text { Exp. } 2\end{array}$} & $\begin{array}{l}\text { Experienced } \\
\text { Experienced }\end{array}$ & $\begin{array}{l}39 \cdot 2 \pm 12 \cdot 6(9) \\
22 \cdot 3 \pm 3 \cdot 1(5)\end{array}$ & $\begin{array}{l}50 \cdot 1 \pm 2 \cdot 9(13) \\
32 \cdot 8 \pm 9 \cdot 5(9)\end{array}$ & $3 \cdot 9 \pm \overline{0 \cdot 3}(7)$ & $4 \cdot 8 \pm 0.5(11)$ \\
\hline & & Intromissions only & $\begin{array}{l}\text { Intromissions } \\
\text { plus ejaculation }\end{array}$ & & $\begin{array}{c}\text { Test cage } 15 \text { min } \\
\text { no females }\end{array}$ \\
\hline $\begin{array}{l}\text { Exp. } 3 \\
\text { Exp. } 4\end{array}$ & $\begin{array}{l}\text { Naive } \\
\text { Same rats as } \\
\text { Exp. } 3 \text { when } \\
\text { experienced }\end{array}$ & $\begin{array}{l}16 \cdot 8 \pm 4 \cdot 3(8) \\
25 \cdot 8 \pm 5 \cdot 4(11)\end{array}$ & $\begin{array}{l}14 \cdot 0 \pm 5 \cdot 6(6) \\
27 \cdot 8 \pm 7 \cdot 2(9)\end{array}$ & & $\begin{array}{c}3 \cdot 0 \pm 1 \cdot 2(4) \\
-\end{array}$ \\
\hline
\end{tabular}

Values expressed in $\mathrm{mg} / 100 \mathrm{ml}$ plasma, group means \pm S.E. with number of observations in parentheses in male rats under different conditions.

In Exp. 1, male rats, all of which had had three to five previous mating tests during which ejaculation(s) had occurred ('Experienced males') were allowed to copulate for 15 or 30 min under observation or were placed in the observation cage alone for $30 \mathrm{~min}$, after which blood samples were obtained. The results are given in Table 1. A marked increase in plasma $\mathrm{Hb}$ concentration was observed in rats that had copulated as compared to the control value of $3 \cdot 6 \pm 0 \cdot 7$ (twelve observations) in plasma from rats bled immediately after being taken from their home cage. Simply placing the rats in the test cage for $30 \mathrm{~min}$ in the absence of a female had no effect (Exp. 1, Table 1). In a second experiment with 'experienced males', high values were again observed in rats that copulated for 15 or $30 \mathrm{~min}$ (Exp. 2, Table 1). The control group in this experiment consisted of rats which were allowed to mount receptive females for $30 \mathrm{~min}$, intromission being prevented by taping the female as described above. Plasma $\mathrm{Hb}$ concentration in this group remained low despite the occurrence of between sixty-one and eighty-four vigorous attempts by each rat to achieve intromission. In both Exps 1 and 2, rats copulating for 30 min had higher mean plasma $\mathrm{Hb}$ concentrations than those copulating for only $15 \mathrm{~min}$, but the differences were not statistically significant. In Exps 3 and 4, the effects of intromission alone 
and intromission plus ejaculation on plasma $\mathrm{Hb}$ concentration were compared. The animals were bled immediately after their first behavioural test during which they were allowed ten to twelve intromissions over a period of about $15 \mathrm{~min}$ or ten to fifteen intromissions plus an ejaculation. Subsequently, they were allowed to mate under observation and were observed to ejaculate at least once in each of four or five test sessions; the original experimental procedure was then repeated. Neither in naïve nor in 'experienced' animals was there a significant difference between the plasma $\mathrm{Hb}$ concentrations of the two groups (Exps 3 and 4, Table 1). Plasma $\mathrm{Hb}$ concentrations were higher in the 'experienced' animals but the differences were not statistically significant. Erections alone, induced under pentobarbitone sedation, had no effect on plasma $\mathrm{Hb}$ concentrations. The mean value in nine rats showing erections was $4 \cdot 1 \pm 1.8$ and $4 \cdot 1 \pm 1.3$ in four rats manipulated in the same way but failing to show erections and these were not significantly different from the values for any other control group in the present series of experiments.

It is clear from these results that normal copulation promptly increases plasma haemoglobin concentration in male rats. Penile intromissions without ejaculation are sufficient to produce this effect but repeated mounts without intromission even in far greater numbers than those occurring in a normal ejaculatory series do not have this effect nor does the artificial induction of repeated erections under barbiturate sedation. The cause of these changes in the male rat are not known but the failure of repeated mounts to increase plasma haemoglobin concentration suggests that it is not a non-specific effect related to the test situation. It would be of interest to know whether this consequence of copulation on the part of the male is peculiar to the rat or is of more general occurrence. 